\title{
Toward the Identification of Two Glycoproteins Involved in the Stomatal Deregulation of Downy Mildew-Infected Grapevine Leaves
}

\author{
Christelle Guillier, ${ }^{1}$ Magdalena Gamm, ${ }^{2}$ Géraldine Lucchi, ${ }^{3}$ Caroline Truntzer, ${ }^{3}$ Delphine Pecqueur, ${ }^{3}$ \\ Patrick Ducoroy, ${ }^{3}$ Marielle Adrian, ${ }^{2}$ and Marie-Claire Héloir ${ }^{2}$
}

${ }^{1}$ CNRS, UMR1347 Agroécologie, ERL CNRS 6300, BP 86510, F-21000 Dijon, France; ${ }^{2}$ Université de Bourgogne, UMR1347 Agroécologie, ERL CNRS 6300, BP 86510, F-21000 Dijon, France; ${ }^{3}$ Clinical Innovation Proteomic Platform - CLIPP, 15 Boulevard Maréchal de Lattre de Tassigny, BP37013, F-21070 Dijon cedex, France

Submitted 26 May 2015. Accepted 15 June 2015.

\begin{abstract}
Stomata remain abnormally opened and unresponsive to abscisic acid in grapevine leaves infected by downy mildew. This deregulation occurs from 3 days postinoculation and increases concomitantly with leaf colonization by the pathogen. Using epidermal peels, we demonstrated that the active compound involved in this deregulation is located in the apoplast. Biochemical assays showed that the active compound present in the apoplastic fluids isolated from Plasmopara viticola-infected grapevine leaves (IAF) is a CysCys bridge-independent, thermostable and glycosylated protein. Fractionation guided assays based on chromatography coupled to stomatal response and proteomic analysis allowed the identification of both plant and pathogen proteins in the active fraction obtained from IAF. Further in silico analysis and discriminant filtrations based on the comparison between predictions and experimental indications lead to the identification of two Vitis vinifera proteins as candidates for the observed stomatal deregulation.
\end{abstract}

Plasmopara viticola ([Berk. \& M.A. Curtis] Berl \& De Toni) is the causal agent of grapevine downy mildew, a severe disease that can cause severe losses of yield. This obligate biotrophic oomycete infects all green parts of the plants. During its asexual cycle, it penetrates via stomata and develops intercellular mycelium with haustoria for nutrient uptake from host cells. In well-colonized leaves, symptoms appear as typical yellow areas called 'oil spots' on the adaxial side. On the abaxial leaf surface, upon high hygrometry, sporulation occurs when sporangiophores emerged through stomata (Gessler et al. 2011). Therefore, pores play a major role in the infection cycle of the pathogen, since they constitute the penetration site for germinating zoospores as well as the exit sites for sporangiophores during sporulation. In addition, it was reported that a decrease of stomatal density is correlated with a lower susceptibility to Plasmopara viticola (Alonso-Villaverde et al. 2011).

Stomata allow plant gas exchanges for photosynthesis and transpiration. Their movements are finely regulated by

Corresponding author: C. Guillier; E-mail: christelle.guillier@dijon.inra.fr

*The $\boldsymbol{e}$-Xtra logo stands for "electronic extra" and indicates that one supplementary figure and two supplementary tables are published online.

This article is in the public domain and not copyrightable. It may be freely reprinted with customary crediting of the source. The American Phytopathological Society, 2015. environmental or endogenous factors such as phytohormones, light, $\mathrm{CO}_{2}$ level, air humidity, and abiotic or biotic stresses (Outlaw 2003; McLachlan et al. 2014; Vavasseur and Raghavendra 2005). They are modulated by well-known events occurring in guard cells, including the activation or deactivation of the plasma membrane $\mathrm{H}^{+}$ATPase and inward or outward $\mathrm{K}^{+}$ channels responsible for water fluxes (Edwards et al. 1988; Roelfsema and Hedrich 2005). These events are regulated by a complex signaling network including protein kinases, $\mathrm{Ca}^{2+}$, nitric oxide, reactive oxygen species, and organic acids (Araújo et al. 2011; Garcia-Mata et al. 2003; Murata et al. 2015; Schroeder et al. 2001a). Beside the role of plasma membrane ion channels and transporters, changes in stomatal aperture also involve reorganization of the cytoskeleton, alteration of metabolism, and transcriptional reprogramming. To summarize these events, in silico models of guard cell signaling have been proposed (Schroeder et al. 2001b), especially for light-induced stomatal opening and abscisic acid (ABA)-induced stomatal closure (Sun et al. 2014).

We have previously reported a stomatal dysfunction in P. viticola-infected grapevine leaves (Allègre et al. 2007). Indeed, stomata remain open in darkness, during a water stress, or after ABA treatment. In our greenhouse conditions, this abnormal stomatal opening occurs from 3 days postinoculation (dpi), before symptom expression, increases during infection, and reaches its maximal point at the end of the infection cycle ( 6 to $7 \mathrm{dpi}$ ), probably to facilitate exit of the pathogen. Other examples of modulation of the stomatal behavior by pathogens have been reported (McLachlan et al. (2014). For some plant species, stomatal closure is one of the first defense responses against microorganisms that use these pores as an entry point (Sawinski et al. 2013). However, some pathogens secrete compounds, called effectors, to counteract this stomatal innate immunity, either by preventing stomatal closure or reopening closed stomata (Chang et al. 2005). For example, syringolin A secreted by some strains of Phytophthora syringae pv. syringae affects stomatal closure in bean and Arabidopsis by proteasome inhibition (Schellenberg et al. 2010). Conversely, coronatine (COR), a toxin produced by some Pseudomonas syringae pathovars induces stomatal reopening of closed stomata via the activation of plasma membrane $\mathrm{H}^{+}$ATPase (Melotto et al. 2006, 2008). Interestingly, COR also overcomes dark-induced stomatal closure in broad bean and Italian ryegrass (Mino et al. 1987). In peach- and almond-Fusicoccum amygdali interactions, the fusicoccin toxin secreted by the fungus also stimulates the plasma membrane pump leading to an abnormal 
stomatal opening in darkness (Baunsgaard et al. 1998; Turner and Graniti 1976).

Other pathogens open stomata via the accumulation of organic compounds, probably to facilitate their exit. Farrell et al. (1969) suggested that, in potato leaves infected by Phytophthora infestans, stomatal deregulation may be the result of the higher accumulation of soluble sugars in the guard cells of infected leaves, leading to stomatal opening. In Vicia fabaSclerotinia sclerotiorum interaction, oxalate produced by the fungus alters guard cell osmoregulation and interferes with ABA-induced closure (Guimarães and Stotz 2004).

In Plasmopara viticola-grapevine interaction, the stomatal deregulation increases progressively and concurrently with leaf colonization until the emergence of sporangiophores, suggesting that the observed abnormal opening might facilitate dissemination of the pathogen. According to previous results, this deregulation is likely to be induced by a nonsystemic compound produced by the oomycete or the plant during infection (Allègre et al. 2007). As guard cells lose connections to neighboring cells during development, potential signal molecules need to pass the apoplastic space to reach stomata. The apoplast is constituted by the cell walls, extracellular spaces, and freemoving fluid, usually called apoplastic fluids (AF). As it contains numerous and various compounds, including ions, hormones, amino acids, sugars, gas, and proteins, AF plays a crucial role in various processes, e.g., plant homeostasis, growth regulation, defense mechanisms, and also, stomatal movements (Dietz 1997; Roelfsema and Hedrich 2002; Sakurai 1998).

In this context, we hypothesized that the active component responsible for grapevine stomatal deregulation is present in the apoplast. AF were, therefore, isolated from mock and Plasmopara viticola-infected grapevine leaves and were applied on epidermal peels to assess stomatal response. We showed that the active compound is, indeed, located in AF, and biochemical assays revealed that it is a glycosylated protein. Further proteomic analysis and in silico predictions led us to retain two candidates. Their potential implication in the stomatal deregulation is discussed.

\section{RESULTS}

\section{AF recovery.}

As stomatal deregulation is maximal at the late stage of infection, AF were isolated from mock and Plasmopara viticola-inoculated leaves (noted healthy $[\mathrm{HAF}]$ and inoculated
[IAF], respectively) at $6 \mathrm{dpi}$ using an adapted vacuum infiltration centrifugation method. AF were obtained with a yield of $40 \mu \mathrm{l}$ per gram of infiltrated leaf fresh weight, and quality was checked after determination of the contamination level. Common markers, i.e., malate dehydrogenase (c-mdh) and RuBisCo large subunit, were used to evaluate the cytoplasmic contamination of $\mathrm{AF}$ in comparison with total leaf extracts. The measured activity of c-mdh in HAF and IAF corresponded to 2 and $7 \%$, respectively, of the total leaf extract activity, whereas RuBisCo was only detected in total leaf samples (Supplementary Fig. S1), indicating that contamination was low enough to be acceptable.

\section{IAF induces stomatal deregulation.}

HAF and IAF were both tested on epidermal peels to assess their effects on stomatal movements in darkness. HAF had no significant effect, with a stomatal aperture around $4 \mu \mathrm{m}$, similar to the control value, whereas IAF induced a stomatal opening of about $2 \mu \mathrm{m}$ compared with the control (Fig. 1A).

We subsequently investigated whether IAF were able to oppose an ABA effect. AF were applied together with $50 \mu \mathrm{M}$ ABA at light. IAF inhibited the ABA-induced stomatal closure, while HAF had no effect (Fig. 1B). Hence, IAF treatment of epidermal peels mimics the stomatal deregulation observed in planta, i.e., an abnormal stomatal opening in darkness and an inhibition of ABA-induced closure, suggesting that IAF contain one or more compounds responsible for the deregulation.

In order to investigate a possible activation of $\mathrm{H}^{+}$ATPase in this deregulation, epidermal peels were treated by IAF or fusicoccin (positive control) in darkness before application of orthovanadate, an inhibitor of the $\mathrm{H}^{+}$ATPase pump. Interestingly, IAF induced a stomatal opening in a similar manner as fusicoccin. As expected, orthovanadate inhibited fusicoccininduced opening of stomata, but curiously, it had no effect on IAF-opened stomata (Fig. 1C), suggesting that $\mathrm{H}^{+}$ATPase is not clearly involved in the response to IAF.

\section{Stomatal opening is induced by a glycoprotein.}

Different treatments were tested on IAF to determine the biochemical characteristics of the active compound responsible for the stomatal deregulation (Fig. 2A). After pronase treatment, IAF lose their ability to induce stomatal opening $(+0.8$ and $2.3 \mu \mathrm{m}$ compared with the control for pronase-treated and untreated IAF, respectively), suggesting that the active compound is a protein. Denaturing treatments as disulfide bond reduction (dithiothreitol [DTT] treatment) or heating (up to $95^{\circ} \mathrm{C}$ ) did not
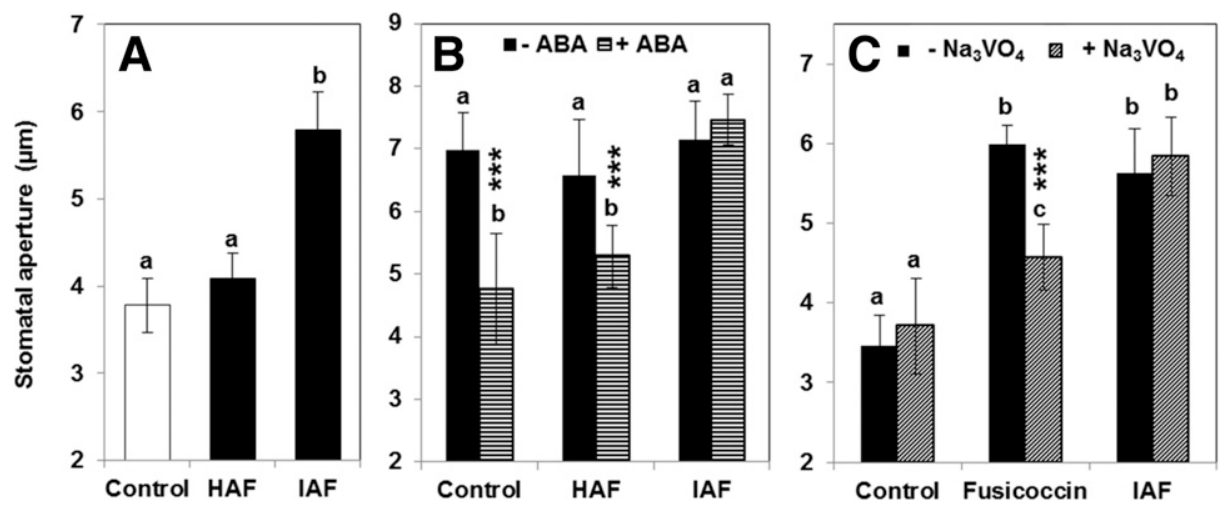

Fig. 1. Effect of apoplastic fluids (AF) and fusicoccin on the stomatal aperture of grapevine leaf epidermal peels. A, Epidermal peels were incubated in darkness with either AF obtained from healthy (HAF) or Plasmopara viticola-infected (IAF) grapevine leaves or buffer (Control). B, Light-conditioned epidermal peels were incubated with buffer (Control), HAF, or IAF alone (black bars) or were mixed with $50 \mu \mathrm{M}$ abscisic acid (ABA) (striped bars). C, Epidermal peels were incubated with buffer (Control), IAF, or $1 \mu \mathrm{M}$ fusicoccin alone (black bars) or were mixed with $1 \mathrm{mM}$ orthovanadate $\left(\mathrm{Na}_{3} \mathrm{VO}_{4}\right)(\mathrm{striped}$ bars). All stomatal aperture measurements were performed $2 \mathrm{~h}$ after treatment. Values of all tests were obtained from four individual experiments and letters indicate significant differences (Fisher's least significant difference test) between treatments. Asterisks denote significant differences between a treatment and its control counterpart (Fisher's test annotations: Asterisks (***) indicate $P<0.0001$ ). 
significantly affect IAF activity, suggesting the stability of the protein compound. A deglycosylation treatment by sodium metaperiodate led to around $80 \%$ reduction of the IAF activity on stomatal opening. Altogether, these data suggest that the active compound is a thermostable glycoprotein (Fig. 2A).

Further experiments were carried out to restrict the widerange composition of the IAF by size filtration and differential protein precipitations (50 and $75 \%$ ). Epidermal peel assays showed that the active component was present only in the $75 \%$ ammonium sulfate-recovered fraction $(+2.8 \mu$ m compared with control) (Fig. 2B, left panel). In addition, when IAF was split into two fractions using $50-\mathrm{kDa}$ cut-off filters, activity was found only in the upper fraction $(+2.5 \mu \mathrm{m}$ compared with control) (Fig. 2B, right panel). According to these results, AF were pretreated by size-filtering and ammonium sulfate precipitation before further experiments.

In order to confirm that the active compound is a glycoprotein, lectin chromatography was used on either HAF or IAF samples to separate the nonglycosylated protein fraction ([-Gly]) from the glycosylated one ([Gly]) (Fig. 3A). All fractions were tested on epidermal peels to measure stomatal responses and only IAF[Gly] induced stomatal opening. To further purify the active compound, exchange ion chromatography was used to split [Gly] into several fractions ([Fn]) (Fig. 3B) that were tested using epidermal peels. Only the IAF[F10] fraction (eluted at 75 to $100 \mathrm{mM} \mathrm{NaCl}$ ) was active (Fig. 3B). Unfortunately, no further enrichment process was possible since the protein amount was reduced to microgram range.
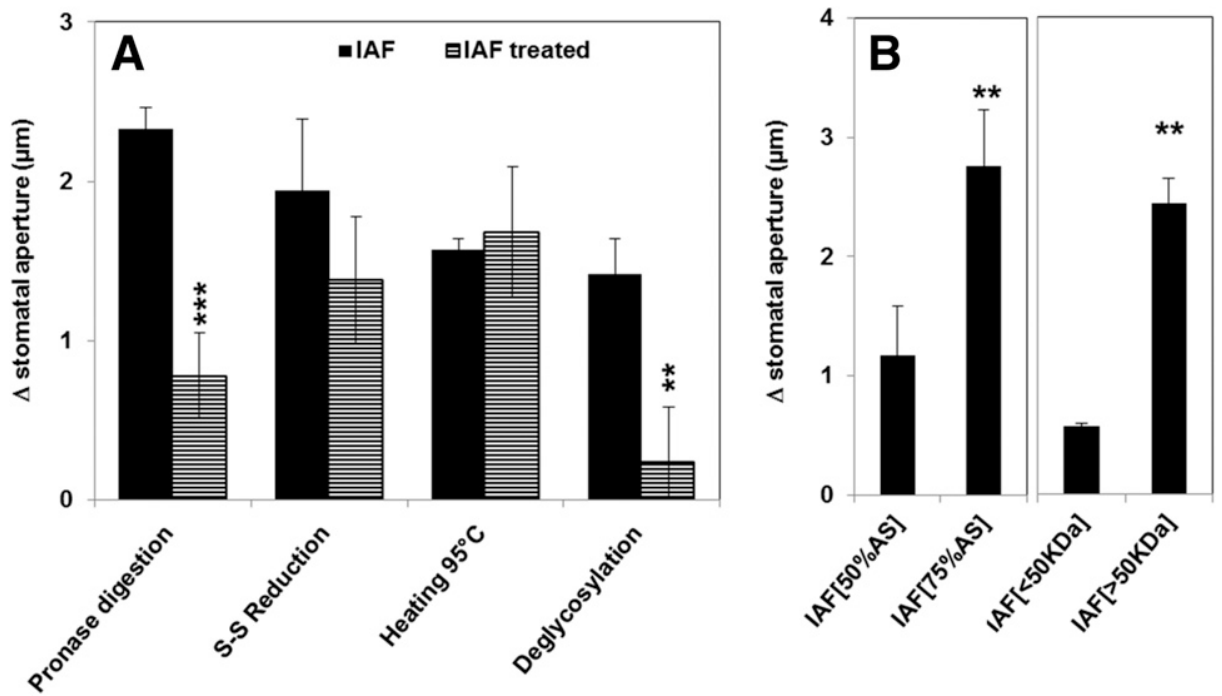

Fig. 2. Biochemical characterization of the stomatal deregulation active compound present in the apoplastic fluids of Plasmopara viticola-infected grapevine leaves (IAF). A, Effects of inhibition treatments on the IAF-induced stomatal opening. Epidermal peels were incubated ( $2 \mathrm{~h}$ in darkness) with crude IAF (dark bars) or treated IAF (striped bars) (pronase digestion, disulfure bridges reduction, heating, and deglycosylation).Values correspond to the difference of stomatal aperture (measured in each condition) compared with buffer control. Experiments were repeated at least twice and asterisks $(*)$ indicate significant difference between the samples and control counterpart (Fisher's test: *** indicate $P<0.0001$ and $* *, P<0.005$ ). B, On the left, effects of protein extracts obtained from IAF after precipitation with 50 and $75 \%$ ammonium sulfate (AS). On the right, effect of two IAF subfractions (over and under, $>50 \mathrm{kDa}$ and $<50 \mathrm{kDa}$ ) obtained using a 50-kDa cutoff filter. Experiments were repeated twice. Asterisks (**) indicate $P<0.05$ on seven individual experiments.
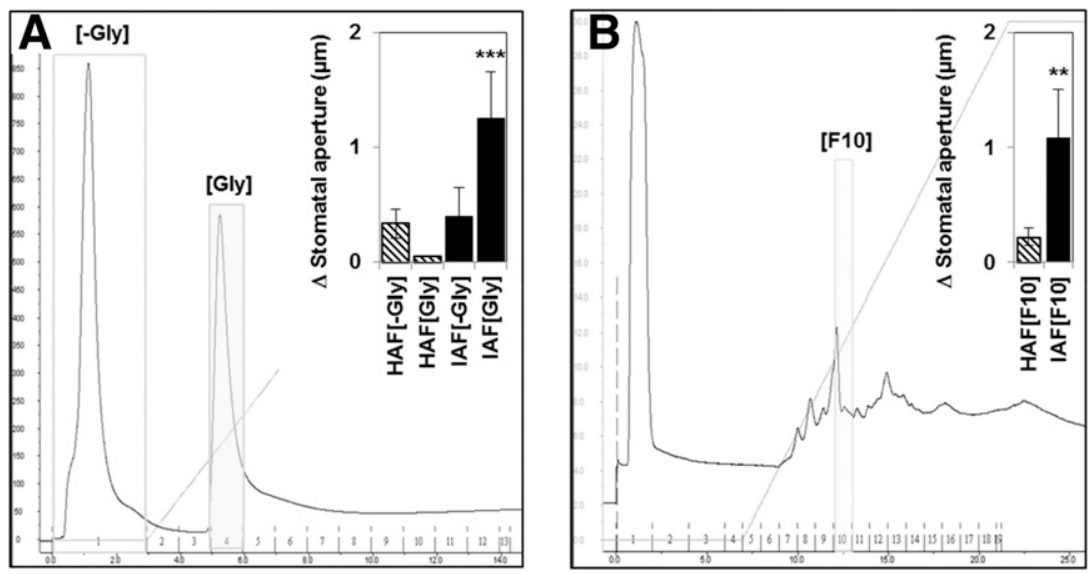

Fig. 3. Purification of the active compound by affinity and ion exchange chromatographies. A, Representative chromatographic profile of apoplastic fluid on a ConA lectin column. After a wash through the unbound nonglycosylated fraction ([-Gly]), the glycosylated proteins ([Gly]) were eluted in one main fraction under a methyl- $\alpha$-D glucopyranoside gradient. The effects of both [-Gly] and [Gly] subfractions of either HAF or IAF were next tested on stomata using epidermal peels (embedded panel). Values correspond to the difference of stomatal aperture measured in response to each subfraction, compared with buffer control. Lectin chromatographies and associated stomatal measurement experiments of the eluted fractions were performed five times. B, Chromatographic profile of [Gly] fractionation on an anion exchange MonoQ column under a $\mathrm{NaCl}$ salt gradient. Void volume and eluted 1-ml fractions were subsequently tested on stomatal aperture using epidermal peels. The activity was centered on fraction 10 [F10] that corresponds to 75 to $100 \mathrm{mM} \mathrm{NaCl}$ (embedded panel). MonoQ chromatographies and associated stomatal measurements experiments of the eluted fractions were performed three times. Asterisks denote significant differences between eluted fractions and buffer control (Fisher's test: three asterisks $(* * *)$ indicate $P<0.0001$ and two $(* *)$ indicate $P<0.001$.). 


\section{Protein identification.}

Mass spectrometry analysis (Nano liquid chromatographytandem mass spectrometry [LC-MS/MS]) was performed on HAF[Gly] and IAF[Gly] to compare both inactive and active glycosylated fractions and on IAF[F10] to identify potential candidates responsible for the stomatal deregulation.

From searches in the database extracted from UniProt (trembl and SwissProt; February 2014; 54,468 entries), 313 peptides allowed identification of a total of 269 Vitis vinifera proteins in the HAF and IAF glycoproteomes. Despite higher variability in the IAF sample, a statistical analysis based on protein identification and quantification perfectly distinguished the HAF[Gly] and the IAF[Gly] samples (Fig. 4A, principal component analysis plot). Among the 269 accessions, significant quantification $(P<0.05)$ were obtained for 223 proteins. Of these, 206 proteins were significantly affected by Plasmopara viticola infection ( $>2.0$ fold and false discovery rate [FDR] $<5 \%$ ), since 35 proteins were less present (-IAF[Gly]) and 171 ones were accumulated (+IAF[Gly]). Also, expression levels of 17 proteins were unchanged (Fig. 4B, 4C). In the IAF[F10] fraction, 24 proteins were identified, and among them, 14 were new ones (i.e., not detected in neither HAF nor IAF[Gly] fractions), raised from the enrichment process. In addition and in comparison with IAF[Gly] protein expression analysis, five proteins belong to the accumulated protein subset, three proteins to the repressed one, and two proteins to the unchanged one (Fig. 4C).

In order to identify proteins of pathogen origin, the Phytophthora infestans (another member of the Peronosporales clade) protein databank was used because the Plasmopara viticola genome sequence is not available. In IAF[Gly] and IAF[F10], 62 and 18 oomycete accessions were obtained, respectively, and only one of them was common to both fractions.

Altogether, these databank queries allowed the preselection of $24 \mathrm{~V}$. vinifera and 18 Phytophthora infestans proteins in the IAF[F10] fraction, (Supplementary Tables S1 and S2). Among the $24 \mathrm{~V}$. vinifera proteins, 19 had either the expected extracellular localization or were indicated as anchored to plasma membrane with a glycosylphosphatidylinositol (GPI) motif. Major functions were described by "Carbohydrate metabolism" and "Proteolysis". Additionally, predictions for the 18 Phytophthora infestans proteins revealed different functions with mainly "Transport", "Cell structure", and "Transcription", but $60 \%$ of the proteins remained unknown. Moreover, only two of them were annotated as extracellular and another five were anchored to the plasma membrane.

In order to decipher between relevant and nonrelevant proteins, in silico predictions were considered. Protein fasta sequences allowed us to obtain information on secondary structure, cellular localization, biochemical characteristics, and putative biological functions. Thus, a selection pipeline (Fig. 5) was designed and applied as follows. The first steps were intended to identify apoplastic and membrane-anchored proteins in $V$. vinifera and secretory proteins in Phytophthora infestans (determined from the Fungal Secretory Database [Choi et al. 2010]). In both cases, proteins containing more than one transmembrane domain (TMHMM predictions) were discarded. For $V$. vinifera, extracellular or proteins anchored to the plasma membrane via a GPI motif (predicted from ProtComp server) were retained. From the Phytophthora infestans list and according to the Fungal Secretome Database, only predicted secreted proteins, i.e, presenting the effector host targeting signal RXLX[EDQ] or RXLR (without the endoplasmic reticulum retention signal [KRHQSA][DENQ]EL) were retained. In the following steps, both $V$. vinifera and Phytophthora infestans candidates having $\mathrm{N}$-glycosylation sites and lacking paired oxidized cysteine residue $\left(\mathrm{Cys}_{\mathrm{ox}}\right)$ were considered, since only glycosylated fraction was active whereas disulfide bond reduction did not significantly affect the stomatal opening. For completeness, proteins exhibiting conserved domains (CD) closely related to guard cells function (according to annotations and literature) were finally picked. At the end of the pipeline, only two $V$. vinifera but no P.infestans proteins gathered essential criteria to be candidates for stomatal dysregulation. Among the two V. vinifera candidates, one contains a lysophospholipase CD (D7TB66) and the other is recognized as a kinase G11A-like protein (F6I571) with a phototropin CD (Table 1).

\section{DISCUSSION}

Several studies depicted the potential role of the whole apoplastic proteome in pathogen perception and plant defense responses during infection (Delaunois et al. 2014; Floerl et al. 2012). The present work investigated the AF proteome of Plasmopara viticola-infected grapevine leaves and revealed that the glycosylated subfraction is responsible for the stomatal deregulation observed previously in planta (Allègre et al. 2007). Glycosylation is a posttranslational modification highly

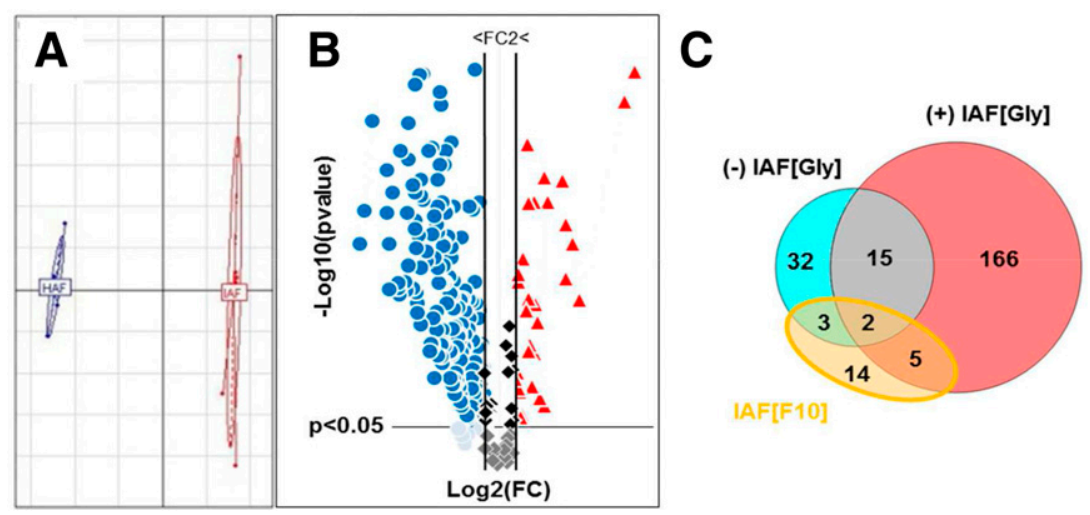

Fig. 4. Analysis of the Vitis vinifera glycosylated fractions of apoplastic fluids (AF). Glycosylated fractions of healthy (HAF) or Plasmapora viticola-infected grapevine leaves (IAF) were obtained from lectin chromatography. The IAF[F10] was then obtained from the IAF[Gly] MonoQ subfraction. A, Normalized principal component analysis of the 269 Vitis vinifera proteins displayed in either HAF[Gly] or IAF[Gly], based on protein identification and quantitation. B, Volcano plot illustration of the $269 \mathrm{~V}$. vinifera AF glycoproteins. Among 223 significant protein ratios $(P<0.05)$, the expression of 206 proteins was significantly changed (>2.0 fold change [FC]) after Plasmopara viticola infection. A total of 171 proteins were accumulated $(\bullet)$ and 35 were repressed $(\boldsymbol{\Delta})$. In addition, 17 proteins kept their expression level unchanged $(\bullet)$. C, Venn diagram distribution of the 24 proteins displayed in IAF[10] over the IAF[Gly] expression subsets (accumulated, +IAF[Gly]; repressed, -IAF[Gly]; and unchanged, overlapping area). 
suspected to be involved in plant defenses and, particularly, in the speed of response, by regulating either the activity or structure of targeted proteins, or both (Delaunois et al. 2014). Affinity ConA lectin chromatography coupled to ion exchange were therefore used to specifically isolate and enrich $\mathrm{N}$-glycoproteins from the AF. Proteomic analysis and a refining process were next undertaken on the apoplastic glycoprotein lists raised from both partners, in order to identify the putative compounds that cause the stomatal deregulation. On the oomycete side, it is interesting to note that, among the 18 Phytophthora infestans displayed proteins, 12 contained the RXLR host-targeting motif and could be translocated into the

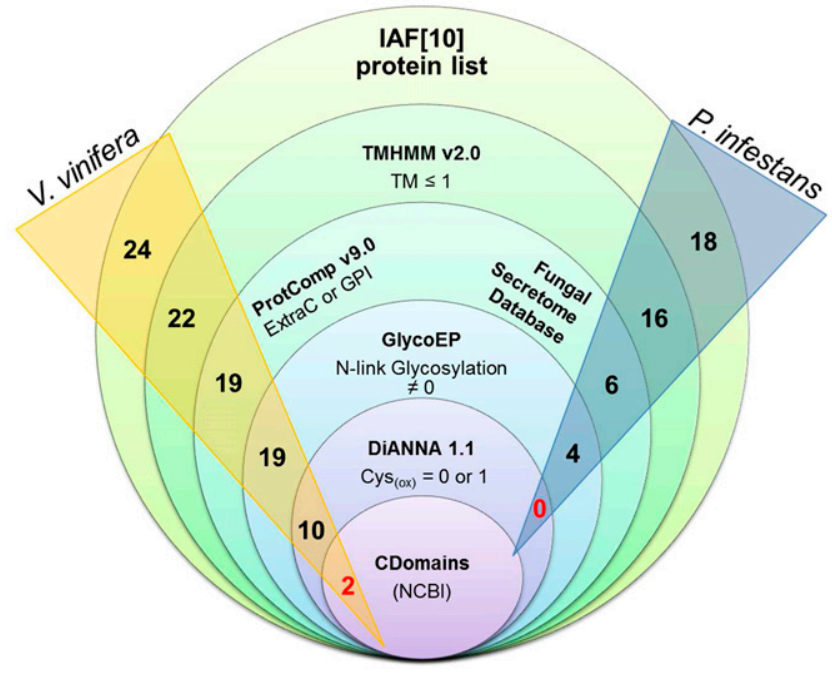

Fig. 5. Multiple step filtering pipeline of the protein list for fraction 10 of Plasmopara viticola-infected grapevine leaves (IAF[F10]). Prediction tools were successively applied on the Vitis vinifera and Phytophthora infestans protein lists (the Phytophthora infestans databank was used for this study because of the lack of a Plasmopara viticola databank). The numbers of proteins that matched to the selective criteria are indicated in bold. The TMHMM program, ProtComp server, and the Fungal Secretome Database (FSD) were used to select extracellular and secretory proteins in $V$. vinifera and Phytophthora infestans, respectively. Only proteins that contain one or no transmembrane domain (TM) were admitted. Among the V. vinifera list, extracellular (ExtraC) and plasma membrane glycosylphosphatidylinositolanchored proteins were retained. In the Phytophthora infestans list, only predicted secreted proteins were retained (according to FSD). Next, additional compulsory criteria were determined from experimental conditions, including the presence of N-glycosylation sites (GlycoEP server) and lack of paired-oxidized cysteine residue $\left[\mathrm{Cys}_{(\mathrm{ox})}\right]$ (estimated with DiANNA software). Finally, proteins containing conserved domains (CDomains; National Center for Biotechnology Information) related to guard cells functioning were picked. host cells via endocytosis after binding to phosphatidyinositol3-phosphate as a receptor (Kale and Tyler 2011; Kale et al. 2010). Therefore, this mechanism would suggest that the apoplast also displays extrahaustorial matrix material (Bouwmeester et al. 2011). However, discrimination pipeline applied on the Phytophthora infestans protein list discarded all the predicted secreted proteins because none of these components matched our biochemical criteria. Noteworthy, as the Phytophthora infestans protein databank was used, one cannot exclude the involvement of a glycoprotein specific to Plasmopara viticola. Unfortunately, there is currently no tool available to check this point.

Among the 10 grapevine proteins that pass the biochemical criteria, some of them (A5C816, E0CQB3, F6HM00, A5BZS1, F6I225) are implicated in plant defense responses (Custers et al. 2004; Dittrich and Kutchan 1991; Figueiredo et al. 2014; Tintu et al. 2012), but only two of them, within the newly identified protein subset, are directly involved in stomatal movements (D7TB66 and F6I571 uncharacterized proteins) and, therefore, were designated as relevant candidates.

The candidate F6I571, is a serine/threonine kinase that contains a phototropin-like CD. Plant phototropins are bluelight receptors that control responses such as phototropism, stomatal opening, and chloroplast movement in order to optimize photosynthetic efficiency (Christie 2007). F6I571 shares sequence homology with phototropin 1 and 2 (phot1, phot2) of Arabidopsis thaliana (around 33\% identity) (Fig. 6A), especially in the $\mathrm{C}$-terminal signaling moiety that triggers constitutive phototropin responses (Aihara et al. 2008; Kong et al. 2007). The N-terminal moiety of the phototropin proteins is involved in photosensory and is called the LOV domain (for light oxygen or voltage sensing). The LOV sequences of phot1 and phot 2 contain cysteine residues (Cys66 and Cys39) involved in interdisulfide bonds leading to the dimerization of the phototropin to sense the blue light (Christie et al. 2002; Salomon et al. 2000). Photoexcitation via the LOV domain leads to activation of the C-terminal kinase domain by autophosphorylation on four serine residues in LOV1 (Ser58, Ser185, Ser350, Ser410) (Sullivan et al. 2008). F6I571 shares neither of these two Cys66 and Cys39 but only the Ser58 residue, which was depicted as equally phosphorylated on phot 1 either in dark or light conditions (Sullivan et al. 2008) (Fig. 6A, alignment sequence). In our case, the absence of these amino acid residues would suggest that F6I571 is not activated by light and its 'LOV-like domain' has here an unknown stimulus. In the C-terminus kinase domain, F6I571 conserves the aspartic acid residue (N720 on Atphot2), which has a key role in stomatal opening, as its miss-sense mutation completely abolishes phot2 physiological responses (Kong et al. 2007). In this latest study, the kinase domain itself was also shown to trigger full stomatal

Table 1. Vitis vinifera putative stomatal dysfunction protein candidates ${ }^{\mathrm{a}}$

\begin{tabular}{|c|c|c|c|c|c|c|c|c|c|c|c|}
\hline \multirow[b]{2}{*}{$\begin{array}{l}\text { UniProt } \\
\text { accession }\end{array}$} & \multirow[b]{2}{*}{ Name } & \multirow[b]{2}{*}{ BLAST } & \multirow[b]{2}{*}{ CD } & \multirow[b]{2}{*}{ Mass (kDa) } & \multirow[b]{2}{*}{ Cys } & \multicolumn{6}{|c|}{ Predictions } \\
\hline & & & & & & Cys (Ox) & $\begin{array}{l}\text { Biological } \\
\text { function }\end{array}$ & $\begin{array}{l}\text { Subcellular } \\
\text { localization }\end{array}$ & SP & TM & N-Gly \\
\hline F6I571 & Unknown & $\begin{array}{l}\text { Protein kinase } \\
\text { g11a like }\end{array}$ & $\begin{array}{l}\text { Catalytic domain of } \\
\text { phototropin-like protein } \\
\text { serine-threonine } \\
\text { kinases / keratin B2 } 2\end{array}$ & 66.7 & 14 & 0 & $\begin{array}{l}\text { Signal } \\
\text { transduction }\end{array}$ & $\mathrm{PM}+\mathrm{GPI}$ & - & - & 1 \\
\hline D7TB66 & Unknown & $\begin{array}{l}\alpha / \beta \text { Hydrolases } \\
\text { superfamily } \\
\text { protein }\end{array}$ & $\begin{array}{l}\text { Putative lysophospholipase/ } \\
\text { BAAT-Acyl-CoA thioester } \\
\text { hydrolase } C \text { terminal } \alpha / \beta \\
\text { hydrolase family }\end{array}$ & 30.1 & 3 & 0 & $\begin{array}{l}\text { Lipid } \\
\text { metabolism }\end{array}$ & ExtraC & - & - & 1 \\
\hline
\end{tabular}

\footnotetext{
${ }^{a}$ Putative stomatal dysfunction protein candidates after discriminant filtering based on structures and functions. Only proteins that gather all the following criteria were selected: transmembrane domain $(\mathrm{TM})=0$ or 1 , Subcellular localization $=$ extracellular (ExtraC) or glycosylphosphatidylinositol (GPI) (plasma membrane anchor), $\mathrm{N}$-glycosylation $\neq 0, \mathrm{Cys}(\mathrm{ox})=0$ or 1 , and conserved domain (CD) related to guard cells.
} 
opening, even in dark conditions. Altogether, F6I571 could function as an atypical phototropin, since it contains the C-terminal kinase signaling domain, but might neither act by dimerization nor be activated with blue light.

Phot 1 and Phot 2 belong to the blue-light signaling pathway (Sun et al. 2014) and activate $\mathrm{H}^{+}$ATPase through a phosphorylation that leads to hyperpolarization of the plasma membrane, which allows $\mathrm{K}^{+}$ uptake through inward-rectifying $\mathrm{K}^{+}\left(\mathrm{K}^{+}\right.$in) channels (Schroeder et al. 1987; Thiel et al. 1992; Wang et al. 2014), inducing the swelling of guard cells and stomatal opening. Conversely, in our experiment, $\mathrm{H}^{+}$ATPase seems not involved in IAF-induced stomatal opening, suggesting an alternative signaling pathway.

\section{A}

PHOT1 ARATH PHOT2 ARAT: F 6 I $57 \overline{1}$ _VITVI

PHOT1 ARAT PHOT2 ARATH F6I571_VITVI

PHOT1 ARATH PHOT2 ARATH

F6I57̄̄_VITVI

PHOT1 ARATH PHOT2 ARATH F6I57̄i VITVI

PHOT1 ARATH PHOT2 ARATH

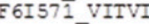

PHOT1 ARATH PHOT2- ARAT F6I571 VITVI

PHOT1 ARATH PHOT2 ARATH F6I57i__VITVI

PHOT1_ARATH PHOT2 ARATH F6I571̄_VITVI

PHOT1 ARATH PHOT2 ${ }^{-}$ARATH F6I57ī_VITVI

PHOT1 ARATH PHOT2 ARAT:

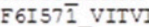

PHOT1 ARATH PHOT2 ARATH F6157̄﹎VITVI
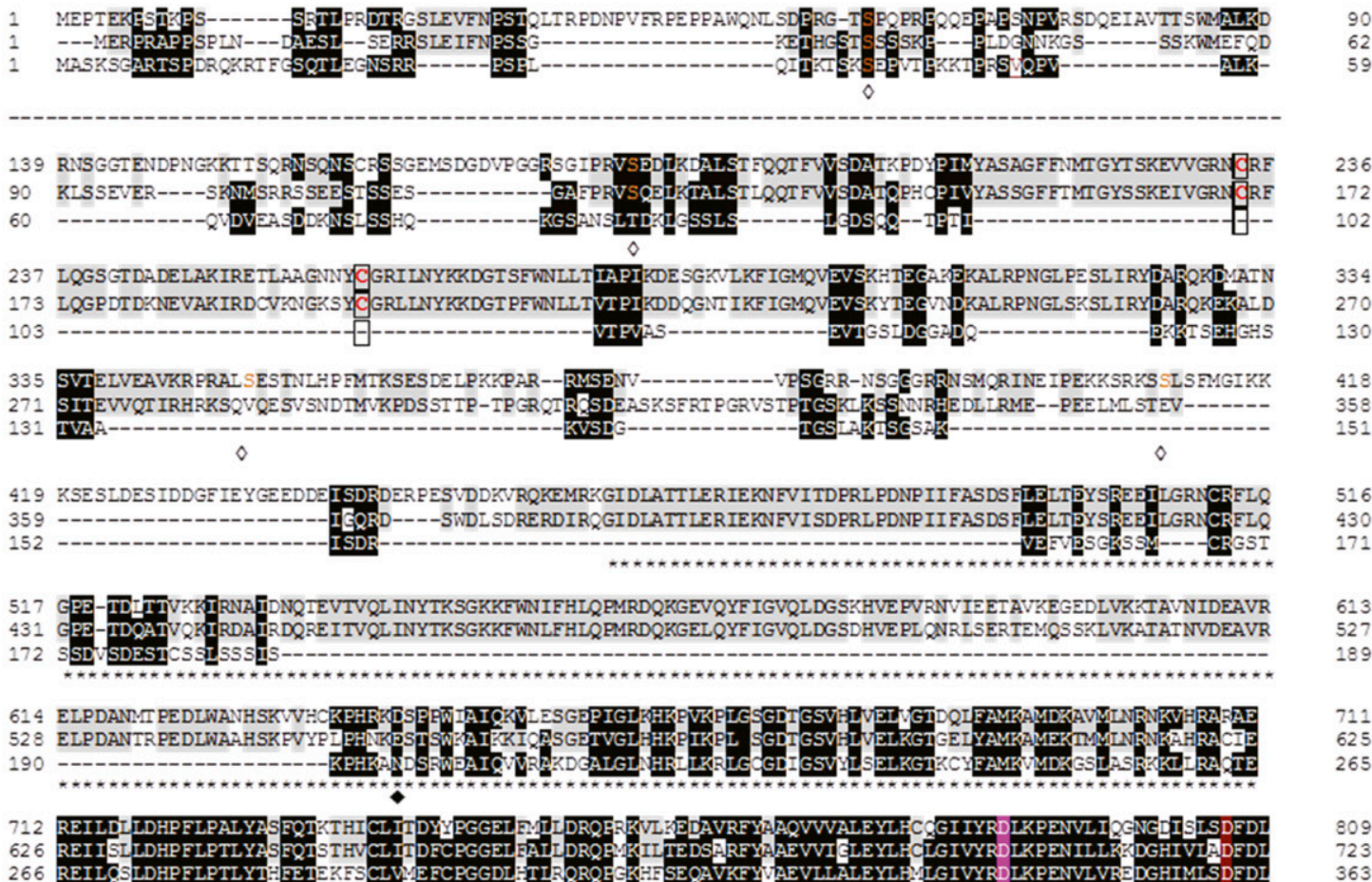

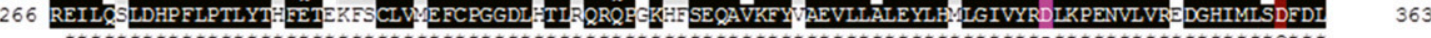

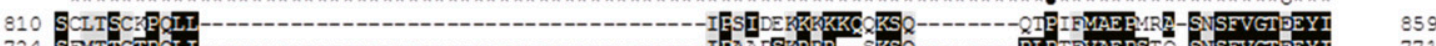

724 SAMTICTP QLI-----

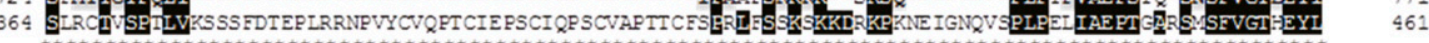

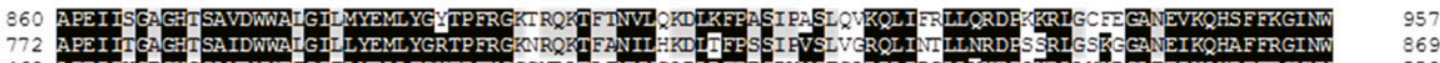

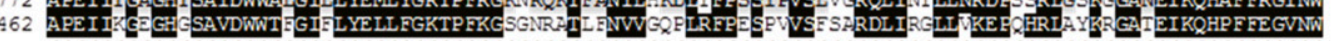

\section{B}

>D7TB66_VITVI

MAQPGSTHDAQSPVIQQQNVI I PNNHGEKLVGTLHETGSPEI VILCHGFRSSKEYTIMVNLAVALENEGISAFRFDFAGNGESE GSFQIGGYWREADDLHAVIQHFRGAKRVIHAILGHSKGGDV VLLYASKYHDVHMVLNVSGRYNLKRGTDEYFGKDFFERIKKD GFFYVKDKTGSFRVTEEGLMDRLSTDMHEACLKIEKDCRVLT IHGSADE I I PVEDAVE FAKI I PNHKLH I IEGANHGYTSHQAE LALVALNFIRTGLQEGKDKP

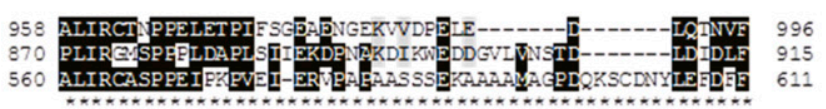

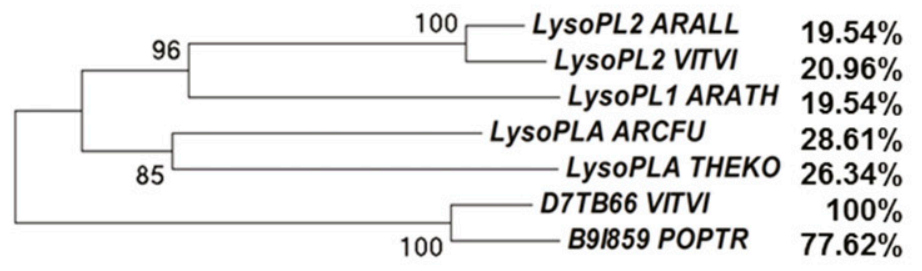

Fig. 6. Sequences of Vitis vinifera stomatal deregulation protein candidates. A, Alignment of F6I571 with phototropins 1 and 2 (phot1 and phot2) from Arabidopsis thaliana. $\bigcirc$ and $\bigcirc$ locate active site and mutation $\mathrm{D} / \mathrm{N}$ that inhibits stomatal opening, respectively; $\bullet$ indicates a potential $\mathrm{N}$-glycosylation site; framed Cs show cysteine residues engaged in disulfide bond; $\diamond$ indicate phosphorylated serines for light-sensing, and asterisks $(*)$ highlight kinase domains. Percent identity: F6I571 to O48963_Phot1 $=19.66 \%$ (40.99\% on the kinase C-terminal sequence), F6I571 to P93025_Phot2 $=26.34 \%$ (42.18\% on the kinase C-terminal sequence). The regions with black background and white lettering corresponds to amino acid residues according to the PAM250 substitution matrix, gray background indicates partial conserved amino acid residues between the three sequences. B, On the left, the D7TB66 sequence with conserved domains and active site. The conserved GXSXG motif is in bold and the lysophospholipase catalytic triad of Ser, Asp, and His residues is underlined. The potential $\mathrm{N}$-glycosylated residue is indicated in italics. On the right, a bootstrap neighbor-joining phylogenetic tree of D7TB66 and other lysophospholipases members using MEGA4.1. The sequence identifiers and UniProt accession numbers are: LysoPLA_ARCFU lysophospholipase AF_1753 (O28521) from Archaeoglobus fulgidus; LysoPLA_THEKO lysophospholipase, $\alpha / \beta$ hydrolase superfamily TK0999 (Q5JIE9) from Thermococcus kodakaraensis; LysoPL2_ARALL esterase/lipase/thioesterase (At1g52760, D7KJK9) from Arabidopsis lyrata; LysoPL2_VITVI lysophospholipase from Vitis vinifera (embl|CAO46025.1, F6HX77); LysoPL1_ARATH $\alpha / \beta$ hydrolase from Arabidopsis thaliana (At2g39400, O80627), and B9I859_POPTR esterase/lipase/thioesterase from Populus trichocarpa (B9I859). PAM250 amino acid identity percentages relative to D7TB66 are indicated. 
The second candidate, D7TB66, is a low-molecular mass protein $(30 \mathrm{kDa})$ that contains a lysophospholipase CD (LysoPLA), defined by the GXSXG motif (lipase consensus sequence) in addition to the $\alpha / \beta$ hydrolase catalytic triad S, D, and H (Fig. $6 \mathrm{~B}$, left panel). Many lysophospholipases were characterized in different organisms, but only a few investigations have been conducted on plants (Gao et al. 2010). Based on published lysophospholipase annotated proteins, sequence comparisons curiously revealed closer identities of D7TB66 with archeal lysophospholipases (26 to $28 \%$ with Archeoglobus and Thermococcus spp., respectively) rather than plants (19 to 20\% with Arabidopsis and Vitis spp.) (Fig. 6B, right panel). LysoPLA from Thermococcus kodakarensis has been shown to be active at a broad range of $\mathrm{pH}(5$ to 8$)$ and at high temperature $\left(70\right.$ to $\left.95^{\circ} \mathrm{C}\right)$ (Cui et al. 2012) that match the biochemically high stability of our active compound. Noteworthy, sequence homologies between annotated lysophospholipases and D7TB66 were very low, while additional phylogenetic analysis allowed identification of a closer member in plant kingdom i.e., B9I859_POPTR from Populus trichoderma (77.6\% sequence identity) (Fig. 6B, right panel), which presents suitable criteria to act as a lysophospholipase (GXSXG motif and catalytic triad SDH). Lysophospholipases hydrolyze the ester bond of lysophospholipids, producing free fatty acids and glycerolphosphate derivatives, and are involved in the regulation of cell functions (Wang and Dennis 1999). Free fatty acids, also produced by phospholipases (Gao et al. 2010), are implicated in various cellular processes (Wang 2004), and they are accumulated in response to abiotic or biotic stresses (Nokhrina et al. 2014). Moreover, these products are known to be involved in stomatal opening either by $\mathrm{H}^{+}$ATPase stimulation (Palmgren et al. 1988) or, more interestingly, by acting directly on inward (activation) and outward $\mathrm{K}^{+}$channels (inhibition) (Lee et al. 1994). This direct action is also reported in the stomatal opening model proposed by Sun et al. (2014).

In summary, two $V$. vinifera glycoproteins, phototropin or lysophospholipase, potentially involved in the stomatal deregulation, were selected from protein lists built from our proteomic approach. They are listed in the dynamic model on stomatal opening regulation scheme proposed in the literature. Further experiments are needed to state their respective roles and how the oomycete induces their accumulation during infection. Overall, this study opens new insight in the understanding of the grapevine-Plasmopara viticola interaction.

\section{MATERIALS AND METHODS}

\section{Biological materials.}

Grapevine (V. vinifera L. cv. Marselan) herbaceous cuttings were grown in individual pots $(10 \times 10 \times 7 \mathrm{~cm})$ containing a mixture of blond peat and perlite $(3: 2, \mathrm{vol} / \mathrm{vol})$ in a greenhouse at a temperature of 24 and $18^{\circ} \mathrm{C}$ (day and night, respectively) and at a relative humidity of $70 \pm 10 \%$ until they developed six leaves. Plants were subirrigated with a fertilizer solution (NPK 10-10-10; Plantin).

The Plasmopara viticola strain was maintained on Marselan plants, and inoculation was performed as previously described (Allègre et al. 2009). Briefly, the lower sides of leaves were sprayed with a suspension of $10^{4}$ sporangia/ml in distilled water, were incubated overnight at a relative humidity of $100 \%$, and were placed in the conditions described above. For experiments, control and Plasmopara viticola-infected grapevine leaves were harvested at $6 \mathrm{dpi}$, when the typical oil spot symptoms were well developed (Allègre et al. 2007).

\section{Isolation of $\mathbf{A F}$.}

$\mathrm{AF}$ were isolated from mock or Plasmopara viticola inoculated leaves (HAF and IAF, respectively), following a modified protocol by Lohaus et al. (2001) and López-Millan et al. (2000), at $6 \mathrm{dpi}$ (when they have their maximal activity, data not shown). After removal of principal veins, leaf fragments were placed in a $50-\mathrm{ml}$ syringe with $25 \mathrm{ml}$ of infiltration buffer (100 mM MES-KOH, $5 \mathrm{mM} \mathrm{KCl,} \mathrm{pH} \mathrm{6.5)} \mathrm{and} \mathrm{were}$ infiltrated by repeated movements of the piston. Excess buffer was removed and the leaf fragments were rolled up with parafilm to obtain a roll of $0.8-\mathrm{cm}$ diameter, which was cut into 1-cm thick slices. These were placed in Eppendorf tubes and the fluids were extracted by centrifugation $(4,000 \times g$, $45 \mathrm{~min}, 18^{\circ} \mathrm{C}$ ).

\section{Epidermal disc model and stomatal movement bioassays.}

Epidermal discs were prepared following a modified protocol described by Allègre et al. (2009). Briefly, leaves of noninoculated plants were harvested at the end of the dark period, in order to ensure that most stomata were closed at the onset of the treatments. Leaf discs were excised using a $0.8-\mathrm{cm}$ diameter punch and the lower epidermis was fixed on a thin layer of silicone glue (Telesis 5; Premiere Products) on a microscope cover slide $(20 \times 20 \mathrm{~mm})$. The upper epidermis and mesophyll were scraped off with a metal forceps. The remaining lower epidermis was washed in distilled water and was incubated in equilibrium buffer (10 mM MES-KOH, $\mathrm{pH} 6.5)$ for $30 \mathrm{~min}$ in the dark at room temperature (RT). After this equilibration step, $10 \mu$ of sample (discussed below) was applied directly to the epidermal disc and the microscope cover slide was placed, face down, over a thick rubber ring, allowing a 'hanging drop' incubation (avoiding evaporation) and was left in the dark for $2 \mathrm{~h}$ at RT, prior to stomatal aperture measurements. Before observations, epidermal discs were incubated for 2 min with $20 \mu \mathrm{g}$ of fluorescein diacetate per milliliter, in order to visualize stomata presenting living guard cells. Photos of stomata were taken under epifluorescence with a magnification of 400 (microscope DMLB, Leica Microsystems; filter L5: $\lambda_{\text {ex }} 480$ to $540 \mathrm{~nm}, \lambda_{\mathrm{em}}$ 527 to $630 \mathrm{~nm}$ ) and were analyzed with NIS-Elements BR software (Nikon Instruments). The stomatal aperture was measured from data pictures using MesurimPro software version 3.4 (developed by J.-F. Madre, Amiens, France). Two leaf discs per treatment (about 100 stomata in total) were analyzed and all experiments were repeated at least twice. Data were analyzed using analysis of variance combined with a Fisher's least significant difference.

\section{Biochemical characterization of active components.}

All treatments were realized using $50 \mu \mathrm{l}$ of AF. When necessary, protein fractions were washed through Microcon filters (Amicon, Millipore; 3-kDa cutoff; centrifugation at 14,000 $\times g$, 15 min, 10 times) to remove excess chemical reagents and to change the reaction buffer against the stomatal bioassay buffer (100 mM MES KOH, $5 \mathrm{mM} \mathrm{KCl,} \mathrm{pH} \mathrm{6.5).} \mathrm{Protein} \mathrm{concen-}$ trations of the $\mathrm{AF}$ and further subfractions were determined with the RCDC assay kit (Bio-Rad) and bovin serum albumin as standard.

Protein digestion was performed by adding $2 \mathrm{mg}$ of pronase per milliliter (from S. griseus; Sigma-Aldrich) with $10 \mathrm{mM}$ $\mathrm{CaCl}_{2}$ to the extract and incubating at $50^{\circ} \mathrm{C}$ for $3 \mathrm{~h}$. Treated sample $(15 \mu \mathrm{l})$ was next analyzed by sodium dodecyl sulfatepolyacrylamide gel electrophoresis, to verify that digestion was complete (data not shown). For chemical deglycosylation assays, $\mathrm{AF}$ samples were treated with $5 \mathrm{mM}$ sodium metaperiodate and the reaction was performed at $4^{\circ} \mathrm{C}$ for $16 \mathrm{~h}$.

For reduction of disulfide bonds, $10 \mathrm{mM}$ DTT was added to $50 \mu \mathrm{l}$ of $\mathrm{AF}$ sample (diluted in $100 \mathrm{mM}$ Tris- $\mathrm{HCl}, \mathrm{pH}$ 7.8) and was incubated for $45 \mathrm{~min}$ (at RT). The reaction was then stopped by the addition of $20 \mathrm{mM}$ iodoacetamide and the sample was incubated again for 45 min in dark. 
For all treatments, buffer (i.e., the stomatal bioassay buffer: $100 \mathrm{mM}$ MES KOH, $5 \mathrm{mM} \mathrm{KCl}, \mathrm{pH}$ 6.5) treated in the same way was used as control in the epidermal peel experiments, to ensure that there was no secondary effect on stomatal aperture.

\section{Sample preparation and fractionation.}

$\mathrm{AF}$ were first precipitated by $50 \%$ ammonium sulfate and were centrifuged at $10,000 \times g$ for $30 \mathrm{~min}$. The supernatant was collected and proteins were precipitated by ammonium sulfate (final concentration $75 \%)$. After centrifugation $(10,000 \times g$ for $30 \mathrm{~min}$ ), proteins from the pellet were solubilized in buffer adapted to the further experiments (stomatal bioassay or affinity chromatography). In order to remove ammonium sulfate salts, samples were washed through Microcon filters (50-kDa cutoff, 10 times).

For Lectin ConA affinity chromatography, $500 \mu \mathrm{l}$ of protein samples previously washed (as indicated above) with lectin equilibrium buffer ( $20 \mathrm{mM}$ Tris- $\mathrm{HCl}, 0.5 \mathrm{M} \mathrm{NaCl}, 1 \mathrm{mM}$ $\mathrm{MnCl}_{2}, 1 \mathrm{mM} \mathrm{CaCl}_{2}, \mathrm{pH}$ 7.4) were loaded onto a 1-ml HiTrap ConA column (GE Healthcare) under a $0.4 \mathrm{ml} / \mathrm{min}$ flow rate on a fast protein liquid chromatography (FPLC) AKTA purifier pump (Amersham Biosciences, equipped with UNICORN software). After elution of the void volume containing [-Gly] proteins, the column was washed with the equilibrium buffer and glycoproteins were then stripped off the column by a linear gradient ( 0 to $55 \%, 45 \mathrm{~min}$ ) of buffer containing $20 \mathrm{mM}$ Tris $\mathrm{HCl}, 0.5 \mathrm{M} \mathrm{NaCl} \mathrm{pH} 8,0.5 \mathrm{M}$ methyl $\alpha$-D-glucopyranoside. [-Gly] and [Gly] proteins were collected in 1-ml fractions and were concentrated and washed against buffer (adapted to the further experiments), with filter devices as described before.

For ion exchanged chromatography (MonoQ), $500 \mu \mathrm{l}$ of protein samples eluted from lectin ConA affinity chromatography and subsequently washed with MonoQ equilibrium buffer (20 mM Tris-HCl, pH 8) were loaded onto a MonoQ HR column (5/5; Amersham Biosciences). Runs were performed at a flow rate set up at $1 \mathrm{ml} / \mathrm{min}$ using a FPLC AKTA purifier pump (Amersham Biosciences, equipped with UNICORN software). Proteins were eluted under a linear gradient of buffer containing $1 \mathrm{M} \mathrm{NaCl}(0$ to $30 \%)$ and 1-ml fractions were collected, concentrated, and washed against stomatal bioassay buffer.

\section{Proteomic analysis.}

Reduction and alkylation was achieved by incubating samples successively in $10 \mathrm{mM}$ Tris-(2-carboxyethyl)-phosphine and $0.1 \mathrm{M} \mathrm{NH}_{4} \mathrm{HCO}_{3}$ for $30 \mathrm{~min}$ at $37^{\circ} \mathrm{C}$ and in $55 \mathrm{mM}$ iodoacetamide and $0.1 \mathrm{M} \mathrm{NH} \mathrm{NCO}_{3}$ for $20 \mathrm{~min}$. Peptide fragments were obtained after digestion with a solution of $50 \mathrm{mM} \mathrm{NH}_{4} \mathrm{HCO}_{3}$ containing trypsin (12.5 $\mathrm{ng} \mathrm{\mu l}^{-1}$; Promega) for $3 \mathrm{~h}$ at $37^{\circ} \mathrm{C}$. The resulting peptides were acidified with $0.1 \%$ formic acid and were concentrated by evaporation.

Thereafter, peptides were separated using the nanoRSLC pump (Thermo Scientific) fitted with a C18 trapping column (5 $\mu \mathrm{m}$ average particle diameter, $300 \mu \mathrm{m}$ inner diameter $\times 5 \mathrm{~mm}$ length) (Thermo Scientific) and a C18 analytical column $(2 \mu \mathrm{m}$ average particle diameter, $75 \mu \mathrm{m}$ inner diameter $\times 150 \mathrm{~mm}$ length) (Thermo Scientific). A 120-min gradient of acetonitrile was performed and peptides were analyzed by nanoLC-MS/MS using an LTQ-Orbitrap Elite mass spectrometer equipped with the Advion TriVersa NanoMate nanospray source (Thermo Scientific). Full-scan spectra from a mass/charge ratio of 400 to 1,700 were acquired at a resolution of 120,000 full width at half maximum. From each full-scan spectrum, the 20 ions having the highest intensity were selected for fragmentation in the ion trap and a 30-s exclusion time was defined. Three biological replicates of protein samples were analyzed and $1 \mu \mathrm{g}$ of each sample was injected in technical triplicates.
Protein databank searches were performed using the local Mascot (Matrix Science, version: 2.2.04) server and XTandem program (from the Trans Proteomic Pipeline [TPP] v4.7), against either a database extracted from UniProt (trembl and SwissProt; February 2014, 54468 entries) or the Phytophthora infestans proteome at the Broad Institute BLAST database (Haas et al. 2009). Search parameters were: peptide and MS/MS mass tolerances were set at $10 \mathrm{ppm}$ and $0.6 \mathrm{Da}$ respectively, one missed cleavage per peptide was allowed and modifications carbamidomethylation for cysteine and oxidation for methionine were taken into account.

The identification results were analyzed through the TPP, including Peptide- and ProteinProphet. Among the resulting peptides, only those selected in two of the three technical replicates in one biological sample were retained for further analysis. Retention times were aligned using an algorithm based on hierarchical clustering (Lai et al. 2011). Peptides were quantified using the open source MASIC software (Monroe et al. 2008). A $\log$ transformation was applied to all feature intensities. Another filter was applied to peptides so as to retrieve those with too-high interrun variations. This filter was performed for each biological sample. A normalization procedure was performed to remove technical variability (Johnson et al. 2007). Differentials between conditions HAF and IAF were selected using the MSStats package of Rgui (Clough et al. 2009). This method is based on a fixed effect model of analysis of variance for each of the proteins, with a 5\% FDR control. Only proteins with a fold change greater than 2 were retained.

\section{Protein analysis and in silico predictions.}

Alpha-helical transmembrane spans and signal peptides were predicted according to the Phobius algorithm (Käll et al. 2004) and SignalP v4.1 (Petersen et al. 2011), whereas the online tool PRED-TMBB (Bagos et al. 2004) was employed to discriminate trans-membrane beta-barrel protein domains. Probabilities on cysteine residues in oxidative state (engaged in disulfide bond) were estimated with DiANNA 1.1 web server (Ferrè and Clote 2005). N-glycosylation predictions were inferred from GlycoEP webtool (Chauhan et al. 2013). Biological functions were determined from UniProt annotations and BLAST queries. Conserved domains were determined with the National Center for Biotechnology Information CD database (MarchlerBauer et al. 2011). Subcellular localizations were predicted with ProtComp v9.0 for Plant or Animal/Fungi data when $V$ vinifera or Phytophthora infestans protein lists were used, respectively. RXLR motifs were predicted on Phytophthora infestans proteins with the Fungal Secretome Database (Choi et al. 2010). Phylogenetic tree analysis was conducted using MEGA v4.1 software (Tamura et al. 2007) and a bootstrap test was performed with 1,000 replicates.

\section{ACKNOWLEDGMENTS}

This work received the financial support of the Conseil Régional de Bourgogne and the Bureau Interprofessionnel des Vins de Bourgogne (BIVB). We thank F. Javelle along with M. Rossignol, C. Schaeffer-Reiss, and A. Hovasse for technical support and helpful discussions.

\section{LITERATURE CITED}

Aihara, Y., Tabata, R., Suzuki, T., Shimazaki, K., and Nagatani, A. 2008. Molecular basis of the functional specificities of phototropin 1 and 2. Plant J. 56:364-375.

Allègre, M., Daire, X., Héloir, M. C., Trouvelot, S., Mercier, L., Adrian, M., and Pugin, A. 2007. Stomatal deregulation in Plasmopara viticolainfected grapevine leaves. New Phytol. 173:832-840.

Allègre, M., Héloir, M. C., Trouvelot, S., Daire, X., Pugin, A., Wendehenne, D., and Adrian, M. 2009. Are grapevine stomata involved in the elicitor-induced protection against downy mildew? Mol. Plant Microbe Interact. 22:977-986. 
Alonso-Villaverde, V., Boso, S., Santiago, J. L., Gago, P., and Martinez, M. C. 2011. Variability of the stomata among "Albariño" (Vitis vinifera $L$.) clones and its relationship with susceptibility to downy mildew. Vitis 50:45-46.

Araújo, W. L., Fernie, A. R., and Nunes-Nesi, A. 2011. Control of stomatal aperture: A renaissance of the old guard. Plant Signal. Behav. 6: 1305-1311.

Bagos, P. G., Liakopoulos, T. D., Spyropoulos, I. C., and Hamodrakas, S. J. 2004. PRED-TMBB: A web server for predicting the topology of beta-barrel outer membrane proteins. Nucleic Acids Res. 32: W400-W404.

Baunsgaard, L., Fuglsang, A. T., Jahn, T., Korthout, H. A., de Boer, A. H., and Palmgren, M. G. 1998. The 14-3-3 proteins associate with the plant plasma membrane $\mathrm{H}(+)$-ATPase to generate a fusicoccin binding complex and a fusicoccin responsive system. Plant J. 13:661-671.

Bouwmeester, K., Meijer, H. J. G., and Govers, F. 2011. At the frontier; RXLR effectors crossing the Phytophthora-host interface. Front. Plant Sci. 2:75.

Chang, J. H., Urbach, J. M., Law, T. F., Arnold, L. W., Hu, A., Gombar, S., Grant, S. R., Ausubel, F. M., and Dangl, J. L. 2005. A high-throughput, near-saturating screen for type III effector genes from Pseudomonas syringae. Proc. Natl. Acad. Sci. U.S.A. 102:2549-2554.

Chauhan, J. S., Rao, A., and Raghava, G. P. 2013. In silico platform for prediction of $\mathrm{N}$-, O- and $\mathrm{C}$-glycosites in eukaryotic protein sequences. PLoS ONE 8:e67008.

Choi, J., Park, J., Kim, D., Jung, K., Kang, S., and Lee, Y. H. 2010. Fungal secretome database: Integrated platform for annotation of fungal secretomes. BMC Genomics 11:105

Christie, J. M. 2007. Phototropin blue-light receptors. Annu. Rev. Plant Biol. 58:21-45.

Christie, J. M., Swartz, T. E., Bogomolni, R. A., and Briggs, W. R. 2002. Phototropin LOV domains exhibit distinct roles in regulating photoreceptor function. Plant J. 32:205-219.

Clough, T., Key, M., Ott, I., Ragg, S., Schadow, G., and Vitek, O. 2009. Protein quantification in label-free LC-MS experiments. J. Proteome Res. 8:5275-5284.

Cui, Z., Wang, Y., Pham, B. P., Ping, F., Pan, H., Cheong, G. W., Zhang, S., and Jia, B. 2012. High level expression and characterization of a thermostable lysophospholipase from Thermococcus kodakarensis KOD1. Extremophiles 16:619-625.

Custers, J. H., Harrison, S. J., Sela-Buurlage, M. B., van Deventer, E., Lageweg, W., Howe, P. W., van der Meijs, P. J., Ponstein, A. S., Simons, B. H., Melchers, L. S., and Stuiver, M. H. 2004. Isolation and characterisation of a class of carbohydrate oxidases from higher plants, with a role in active defence. Plant J. 39:147-160.

Delaunois, B., Jeandet, P., Clément, C., Baillieul, F., Dorey, S., and Cordelier, S. 2014. Uncovering plant-pathogen crosstalk through apoplastic proteomic studies. Front. Plant Sci. 5:249.

Dietz, K.-J. 1997. Functions and Responses of the Leaf Apoplast Under Stress. Pages 221-254 in: Progress in Botany. H. D. Behnke, U. Lüttge, K. Esser, J. Kadereit, and M. Runge, eds. Springer, Berlin

Dittrich, H., and Kutchan, T. M. 1991. Molecular cloning, expression, and induction of berberine bridge enzyme, an enzyme essential to the formation of benzophenanthridine alkaloids in the response of plants to pathogenic attack. Proc. Natl. Acad. Sci. U.S.A. 88:9969-9973.

Edwards, M. C., Smith, G. N., and Bowling, D. J. F. 1988. Guard cells extrude protons prior to stomatal opening-A study using fluorescence microscopy and pH micro-electrodes. J. Exp. Bot. 39:1541-1547.

Farrell, G. M., Preece, T. F., and Wren, M. J. 1969. Effects of infection by Phytophthora injestans (Mont.) de Bary on the stomata of potato leaves. Ann. Appl. Biol. 63:265-275.

Ferrè, F., and Clote, P. 2005. DiANNA: A web server for disulfide connectivity prediction. Nucleic Acids Res. 33:W230-W232.

Figueiredo, A., Monteiro, F., and Sebastiana, M. 2014. Subtilisin-like proteases in plant-pathogen recognition and immune priming: A perspective. Front. Plant Sci. 5:739.

Floerl, S., Majcherczyk, A., Possienke, M., Feussner, K., Tappe, H., Gatz, C., Feussner, I., Kües, U., and Polle, A. 2012. Verticillium longisporum infection affects the leaf apoplastic proteome, metabolome, and cell wall properties in Arabidopsis thaliana. PLoS ONE 7:e31435.

Gao, W., Li, H. Y., Xiao, S., and Chye, M. L. 2010. Acyl-CoA-binding protein 2 binds lysophospholipase 2 and lysoPC to promote tolerance to cadmium-induced oxidative stress in transgenic Arabidopsis. Plant J. 62: 989-1003.

Garcia-Mata, C., Gay, R., Sokolovski, S., Hills, A., Lamattina, L., and Blatt, M. R. 2003. Nitric oxide regulates $\mathrm{K}+$ and $\mathrm{Cl}$ - channels in guard cells through a subset of abscisic acid-evoked signaling pathways. Proc. Natl. Acad. Sci. U.S.A. 100:11116-11121.
Gessler, C., Pertot, I., and Perazzolli, M. 2011. Plasmopara viticola: A review of knowledge on downy mildew of grapevine and effective disease management. Phytopathol. Mediterr. 50:3-44.

Guimarães, R. L., and Stotz, H. U. 2004. Oxalate production by Sclerotinia sclerotiorum deregulates guard cells during infection. Plant Physiol. 136 3703-3711.

Haas, B. J., Kamoun, S., Zody, M. C., Jiang, R. H., Handsaker, R. E., Cano, L. M., Grabherr, M., Kodira, C. D., Raffaele, S., Torto-Alalibo, T., Bozkurt, T. O., Ah-Fong, A. M., Alvarado, L., Anderson, V. L., Armstrong, M. R., Avrova, A., Baxter, L., Beynon, J., Boevink, P. C., Bollmann, S. R., Bos, J. I., Bulone, V., Cai, G., Cakir, C., Carrington, J. C., Chawner, M., Conti, L., Costanzo, S., Ewan, R., Fahlgren, N., Fischbach, M. A., Fugelstad, J., Gilroy, E. M., Gnerre, S., Green, P. J., Grenville-Briggs, L. J., Griffith, J., Grünwald, N. J., Horn, K., Horner N. R., Hu, C. H., Huitema, E., Jeong, D. H., Jones, A. M., Jones, J. D., Jones, R. W., Karlsson, E. K., Kunjeti, S. G., Lamour, K., Liu, Z., Ma, L., Maclean, D., Chibucos, M. C., McDonald, H., McWalters, J., Meijer, H. J., Morgan, W., Morris, P. F., Munro, C. A., O’Neill, K., OspinaGiraldo, M., Pinzón, A., Pritchard, L., Ramsahoye, B., Ren, Q. Restrepo, S., Roy, S., Sadanandom, A., Savidor, A., Schornack, S., Schwartz, D. C., Schumann, U. D., Schwessinger, B., Seyer, L., Sharpe, T., Silvar, C., Song, J., Studholme, D. J., Sykes, S., Thines, M., van de Vondervoort, P. J., Phuntumart, V., Wawra, S., Weide, R., Win, J., Young, C., Zhou, S., Fry, W., Meyers, B. C., van West, P., Ristaino, J., Govers, F., Birch, P. R., Whisson, S. C., Judelson, H. S., and Nusbaum, C. 2009 Genome sequence and analysis of the Irish potato famine pathogen Phytophthora infestans. Nature 461:393-398.

Johnson, W. E., Li, C., and Rabinovic, A. 2007. Adjusting batch effects in microarray expression data using empirical Bayes methods. Biostatistics 8:118-127.

Kale, S. D., Gu, B., Capelluto, D. G., Dou, D., Feldman, E., Rumore, A., Arredondo, F. D., Hanlon, R., Fudal, I., Rouxel, T., Lawrence, C. B., Shan, W., and Tyler, B. M. 2010. External lipid PI3P mediates entry of eukaryotic pathogen effectors into plant and animal host cells. Cell 142: 284-295.

Kale, S. D., and Tyler, B. M. 2011. Entry of oomycete and fungal effectors into plant and animal host cells. Cell. Microbiol. 13:1839-1848.

Käll, L., Krogh, A., and Sonnhammer, E. L. 2004. A combined transmembrane topology and signal peptide prediction method. J. Mol. Biol. 338:1027-1036.

Kong, S. G., Kinoshita, T., Shimazaki, K., Mochizuki, N., Suzuki, T., and Nagatani, A. 2007. The C-terminal kinase fragment of Arabidopsis phototropin 2 triggers constitutive phototropin responses. Plant J. 51: 862-873.

Lai, X., Wang, L., Tang, H., and Witzmann, F. A. 2011. A novel alignment method and multiple filters for exclusion of unqualified peptides to enhance label-free quantification using peptide intensity in LC-MS/MS. J. Proteome Res. 10:4799-4812.

Lee, Y., Lee, H. J., Crain, R. C., Lee, A., and Korn, S. J. 1994. Polyunsaturated fatty acids modulate stomatal aperture and two distinct $\mathrm{K}+$ channel currents in guard cells. Cell. Signal. 6:181-186.

Lohaus, G., Pennewiss, K., Sattelmacher, B., Hussmann, M., and Hermann Muehling, K. 2001. Is the infiltration-centrifugation technique appropriate for the isolation of apoplastic fluid? A critical evaluation with different plant species. Physiol. Plant. 111:457-465.

López-Millán, A. F., Morales, F., Abadía, A., and Abadía, J. 2000. Effects of iron deficiency on the composition of the leaf apoplastic fluid and xylem sap in sugar beet. Implications for iron and carbon transport. Plant Physiol. 124:873-884.

Marchler-Bauer, A., Lu, S., Anderson, J. B., Chitsaz, F., Derbyshire, M. K., DeWeese-Scott, C., Fong, J. H., Geer, L. Y., Geer, R. C., Gonzales, N. R., Gwadz, M., Hurwitz, D. I., Jackson, J. D., Ke, Z., Lanczycki, C. J., Lu, F., Marchler, G. H., Mullokandov, M., Omelchenko, M. V., Robertson, C. L., Song, J. S., Thanki, N., Yamashita, R. A., Zhang, D., Zhang, N., Zheng, C., and Bryant, S. H. 2011. CDD: A conserved domain database for the functional annotation of proteins. Nucleic Acids Res. 39: D225-D229.

McLachlan, D. H., Kopischke, M., and Robatzek, S. 2014. Gate control: Guard cell regulation by microbial stress. New Phytol. 203:1049-1063.

Melotto, M., Underwood, W., and He, S. Y. 2008. Role of stomata in plant innate immunity and foliar bacterial diseases. Annu. Rev. Phytopathol. 46:101-122.

Melotto, M., Underwood, W., Koczan, J., Nomura, K., and He, S. Y. 2006. Plant stomata function in innate immunity against bacterial invasion. Cell 126:969-980.

Mino, Y., Matsushita, Y., and Sakai, R. 1987. Effect of coronatine on stomatal opening in leaves of broadbean and Italian ryegrass. Jpn. J. Phytopathol. 53:53-55. 
Monroe, M. E., Shaw, J. L., Daly, D. S., Adkins, J. N., and Smith, R. D. 2008. MASIC: A software program for fast quantitation and flexible visualization of chromatographic profiles from detected LC-MS(/MS) features. Comput. Biol. Chem. 32:215-217.

Murata, Y., Mori, I. C., and Munemasa, S. 2015. Diverse stomatal signaling and the signal integration mechanism. Annu. Rev. Plant Biol. 66:369-392.

Nokhrina, K., Ray, H., Bock, C., and Georges, F. 2014. Metabolomic shifts in Brassica napus lines with enhanced BnPLC2 expression impact their response to low temperature stress and plant pathogens. GM Crops Food 5:120-131.

Outlaw, W. H., Jr. 2003. Integration of cellular and physiological functions of guard cells. Crit. Rev. Plant Sci. 22:503-529.

Palmgren, M. G., Sommarin, M., Ulvskov, P., and Jørgensen, P. L. 1988. Modulation of plasma membrane H+-ATPase from oat roots by lysophosphatidylcholine, free fatty acids and phospholipase A2. Physiol. Plant. 74:11-19.

Petersen, T. N., Brunak, S., von Heijne, G., and Nielsen, H. 2011. SignalP 4.0: Discriminating signal peptides from transmembrane regions. Nat. Methods 8:785-786.

Roelfsema, M. R. G., and Hedrich, R. 2002. Studying guard cells in the intact plant: Modulation of stomatal movement by apoplastic factors. New Phytol. 153:425-431.

Roelfsema, M. R. G., and Hedrich, R. 2005. In the light of stomatal opening: New insights into 'the Watergate'. New Phytol. 167:665-691.

Sakurai, N. 1998. Dynamic function and regulation of apoplast in the plant body. J. Plant Res. 111:133-148.

Salomon, M., Christie, J. M., Knieb, E., Lempert, U., and Briggs, W. R. 2000. Photochemical and mutational analysis of the FMN-binding domains of the plant blue light receptor, phototropin. Biochemistry 39: 9401-9410.

Sawinski, K., Mersmann, S., Robatzek, S., and Böhmer, M. 2013. Guarding the green: Pathways to stomatal immunity. Mol. Plant Microbe Interact. 26:626-632.

Schellenberg, B., Ramel, C., and Dudler, R. 2010. Pseudomonas syringae virulence factor syringolin A counteracts stomatal immunity by proteasome inhibition. Mol. Plant Microbe Interact. 23:1287-1293.

Schroeder, J. I., Allen, G. J., Hugouvieux, V., Kwak, J. M., and Waner, D. 2001a. Guard cell signal transduction. Annu. Rev. Plant Physiol. Plant Mol. Biol. 52:627-658

Schroeder, J. I., Kwak, J. M., and Allen, G. J. 2001b. Guard cell abscisic acid signalling and engineering drought hardiness in plants. Nature 410 : 327-330.

Schroeder, J. I., Raschke, K., and Neher, E. 1987. Voltage dependence of K channels in guard-cell protoplasts. Proc. Natl. Acad. Sci. U.S.A. 84: 4108-4112.
Sullivan, S., Thomson, C. E., Lamont, D. J., Jones, M. A., and Christie, J. M. 2008. In vivo phosphorylation site mapping and functional characterization of Arabidopsis phototropin 1. Mol. Plant 1:178-194.

Sun, Z., Jin, X., Albert, R., and Assmann, S. M. 2014. Multi-level modeling of light-induced stomatal opening offers new insights into its regulation by drought. PLOS Comput. Biol. 10:e1003930.

Tamura, K., Dudley, J., Nei, M., and Kumar, S. 2007. MEGA4: Molecular evolutionary genetics analysis (MEGA) software version 4.0. Mol. Biol. Evol. 24:1596-1599.

Thiel, G., MacRobbie, E. A., and Blatt, M. R. 1992. Membrane transport in stomatal guard cells: The importance of voltage control. J. Membr. Biol 126:1-18.

Tintu, I., Dileep, K. V., Augustine, A., and Sadasivan, C. 2012. An isoquinoline alkaloid, berberine, can inhibit fungal alpha amylase: Enzyme kinetic and molecular modeling studies. Chem. Biol. Drug Des. 80:554-560.

Turner, N. C., and Graniti, A. 1976. Stomatal response of two almond cultivars to fusicoccin. Physiol. Plant Pathol. 9:175-182.

Vavasseur, A., and Raghavendra, A. S. 2005. Guard cell metabolism and CO2 sensing. New Phytol. 165:665-682.

Wang, A., and Dennis, E. A. 1999. Mammalian lysophospholipases. Biochim. Biophys. Acta 1439:1-16.

Wang, X. 2004. Lipid signaling. Curr. Opin. Plant Biol. 7:329-336.

Wang, Y., Noguchi, K., Ono, N., Inoue, S., Terashima, I., and Kinoshita, T. 2014. Overexpression of plasma membrane H+-ATPase in guard cells promotes light-induced stomatal opening and enhances plant growth. Proc. Natl. Acad. Sci. U.S.A. 111:533-538.

\section{AUTHOR-RECOMMENDED INTERNET RESOURCES}

Broad Institute BLAST database:

http://www.broadinstitute.org/annotation/genome/phytophthora_infestans/ Blast.html

DiANNA 1.1 web server: http://clavius.bc.edu/ clotelab/DiANNA

GlycoEP webtool: http://www.imtech.res.in/raghava/glycoep/submit.html

National Center for Biotechnology Information CD database: http://www.ncbi.nlm.nih.gov/Structure/cdd/wrpsb.cgi

Phobius Prediction server: http://phobius.sbc.su.se

PRED-TMBB tool: http://biophysics.biol.uoa.gr/PRED-TMBB/input.jsp

ProtComp programs:

http://linux 1.softberry.com/berry.phtml?topic=index\&group=programs\& subgroup $=$ proloc

SignalP v4.1 server: http://www.cbs.dtu.dk/services/SignalP

UniProt database:

http://www.uniprot.org/uniprot 